\title{
Leptospira patógena en murciélagos de Campeche y Yucatán, México
}

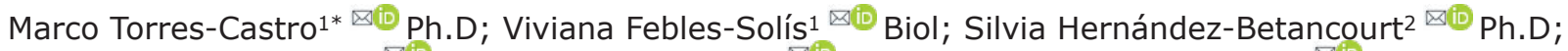

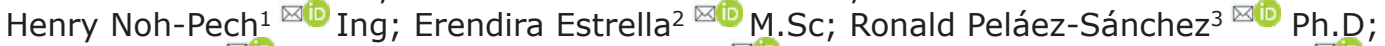

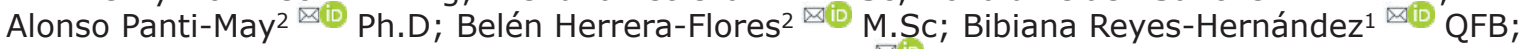 \\ Javier Sosa-Escalante ${ }^{凶(\mathbb{B})}$ M.Sc.
}

\begin{abstract}
${ }^{1}$ Universidad Autónoma de Yucatán, Centro de Investigaciones Regionales "Dr. Hideyo Noguchi", Laboratorio de Enfermedades Emergentes y Reemergentes, Avenida Itzáes x 59, Nro. 490, Mérida, México.

2Universidad Autónoma de Yucatán, Campus de Ciencias Biológicas y Agropecuarias, Departamento de Bioecología Animal, Km. 15.5 carretera Mérida-X'matkuil, Mérida, México.

3Universidad CES, Escuela de Graduados, Grupo de Investigación en Ciencias Básicas, Calle 10 A Nro. 22-04, Medellín, Colombia.

${ }^{4}$ Laboratorio DIMYGEN, Calle 78 Nro. 578, Residencial Pensiones VI, Mérida, México.

*Correspondencia: antonio.torres@correo.uady.mx
\end{abstract}

Recibido: Septiembre 2019; Aceptado: Febrero 2020; Publicado: Mayo 2020.

\section{RESUMEN}

Objetivo. Reportar la infección con Leptospira en riñones de murciélagos de Campeche y Yucatán, México, a través de la amplificación por PCR de dos fragmentos distintos del gen 16S RNA ribosomal. Materiales y métodos. Se realizaron capturas en un sitio de Campeche y dos de Yucatán. A los murciélagos capturados se les aplicó la eutanasia y se les realizó una necropsia para recolectar tejido renal que se usó en la extracción de ADN total. Se realizaron dos PCR convencionales para la amplificación de los fragmentos de $16 S$ RNA ribosomal. Se obtuvieron las secuencias de algunos productos positivos y se analizaron con herramientas bioinformáticas para identificar la especie infectante de Leptospira. Resultados. Se capturaron 69 murciélagos pertenecientes a cuatro familias y a ocho especies distintas. La familia con mayor diversidad fue Phyllostomidae con cinco especies. La especie con mayor frecuencia de captura fue Artibeus jamaicensis (41, 59.4\%). Las PCR arrojaron una frecuencia global de infección de $21.7 \%$. Las especies infectadas fueron $A$. jamaicensis, Pteronotus parnellii y Chiroderma villosum. El análisis bioinformático arrojó un $99.0 \%$ de identidad para Leptospira noguchii, Leptospira borgpetersenii y Leptospira santarosai. Conclusiones. Algunas especies de murciélagos de Yucatán y Campeche son portadores renales de leptospiras patógenas, por lo que podrían participar en el ciclo silvestre de transmisión en la región. La frecuencia de infección encontrada en los riñones de los murciélagos utilizados es mayor en comparación con aquellas obtenidas en otros reservorios de Yucatán y Campeche. Nuevas especies de murciélagos son reportadas como portadores de Leptospira para México.

Palabras clave: Bacteria, epidemiología, espiroquetas, mamíferos, microbiología, quiróptero (Fuentes: DeSC, CAB). 


\section{ABSTRACT}

Objective. To report the infection with Leptospira in the kidneys of bats from Campeche and Yucatán, Mexico, through the amplification by PCR of two different $16 S$ RNA ribosomal gene fragments. Materials and methods. Bat captures were carried out at one site in Campeche and two sites in Yucatán. Euthanasia was applied to the captured bats and a necropsy was performed to collect a renal tissue sample that was used in the total DNA extraction. Two different conventional PCR were performed for the amplification of the $16 S$ RNA ribosomal gene fragments. Some sequences from positive products were obtained and analyzed with bioinformatics tools to identify the infectious species of Leptospira. Results. Sixty-nine bats belonging to four families and eight different species were captured. The family with the greatest diversity was Phyllostomidae with five species. The most captured species was Artibeus jamaicensis (41,59.4\%). Both PCR showed a global infection frequency of $21.7 \%$. The infected species were A. jamaicensis, Pteronotus parnellii, and Chiroderma villosum. The bioinformatic analysis of the positive products yielded a $99.0 \%$ identity for Leptospira noguchii, Leptospira borgpetersenii, and Leptospira santarosai. Conclusions. Some bat species of Yucatán and Campeche, Mexico, are renal carriers of pathogenic Leptospira, therefore participating in the transmission cycle in the region. The frequency of infection found in the renal tissue of the captured bats is higher than the one obtained from other reservoirs captured in Yucatán and Campeche. New species of bats are reported as renal Leptospira carriers in Mexico.

Keywords: Bacteria, chiropter, epidemiology, mammals, microbiology, spirochetes (Source: DeSC, CAB).

\section{INTRODUCCIÓN}

Leptospira es un género de bacterias espiroquetas, perteneciente al orden Spirochaetales y a la familia Leptospiraceae. Según la filogenia más reciente, estas bacterias se dividen en cuatro subclados (P1,P2,S1 y S2) con diferente número de especies, de las cuales las patógenas (subclado P1) ocasionan la leptospirosis en seres humanos y animales (1). Aunque la leptospirosis se considera un problema de salud pública en la población de países en vías de desarrollo, gran parte de los casos no son diagnosticados, debido a que los síntomas son poco específicos y porque la infección generalmente es autolimitante o tiene un curso subagudo. Sin embargo, algunos casos pueden ser mortales por las complicaciones pulmonares o renales $(2,3)$.

Esta enfermedad es una zoonosis endémica en zonas tropicales y subtropicales de México. Su incidencia y prevalencia varían de una región a otra de acuerdo con las características socioeconómicas como las condiciones de higiene y sanitización, y ecológicas como la humedad, temperatura, precipitación pluvial e inundaciones, que coadyuvan en la dispersión y supervivencia de Leptospira en el ambiente. En los estados de Yucatán y Campeche, ubicados en el sureste de México, se han reportado diversas tasas de prevalencia o seroprevalencia por la fuerte influencia de las características socioeconómicas y ecológicas previamente mencionadas $(2,3)$.
Los brotes de leptospirosis humana están asociados principalmente con la presencia de los animales reservorios $u$ hospederos accidentales que excretan leptospiras viables en su orina (debido a que las bacterias colonizan y se reproducen en su tejido renal), la cual contamina el ambiente y los cuerpos naturales (i.e. lagos, lagunas, ojos de agua, cenotes, ríos, etc.) o artificiales de agua (i.e. cisternas, piscinas, represas, tanques, etc.). Los roedores Mus musculus, Rattus rattus y $R$. norvegicus son los reservorios más importantes, por lo que han sido relacionados como la vía de contagio más relevante en poblaciones humanas de algunas regiones tropicales $(3,4)$.

Existen evidencias de que los murciélagos son reservorios de numerosos virus que han ocasionado epidemias en seres humanos y animales $(5,6)$. Recientemente, también han sido involucrados en el ciclo zoonótico de Leptospira a través de la contaminación del medio ambiente o de cuerpos artificiales de agua con su orina. No obstante, las pocas hipótesis sobre los mecanismos de transmisión de las bacterias excretadas por estos animales a las poblaciones humanas o de otros animales, aún son cuestionadas $(7,8)$.

El aumento de los grupos de murciélagos en zonas habitadas por seres humanos se debe a 
alteraciones severas antropogénicas en su hábitat natural o en los sitios de descanso, las cuales facilitan su migración (7). Dichas modificaciones, asociadas a la falta de depredadores naturales, contribuyen a que algunos murciélagos generalistas, habiten y colonicen viviendas o fábricas abandonadas, generando un mayor contacto directo o indirecto (por medio de las excretas) entre ellos y los seres humanos u otros animales (9), aspecto que incrementa también la probabilidad de transmisión accidental de distintos microorganismos patógenos como Leptospira. Debido a esto, los registros de la infección con especies patógenas de Leptospira en murciélagos están incrementándose alrededor del mundo (8). Sin embargo, en México existe un único reporte realizado por Ballados-González et al (10) en el estado de Veracruz, ubicado en el centro-este del país, en el cual se encontraron tres especies positivas a la infección: Artibeus lituratus, Choeroniscus godmani y Desmodus rotundus.

Conocer las especies de leptospiras patógenas que infectan las poblaciones de los murciélagos es el primer paso para evaluar el riesgo de transmisión a los seres humanos y otros animales (11). En este contexto, el objetivo de este estudio fue reportar la infección con Leptospira en riñones de murciélagos de Campeche y Yucatán, México, a través de la amplificación de dos fragmentos distintos del gen $16 S$ RNA ribosomal (16S-rRNA).

\section{MATERIALES Y MÉTODOS}

Lineamientos éticos. La extracción de murciélagos fue aprobada por la Secretaría de Medio Ambiente y Recursos Naturales (SEMARNAT) de México (actas: SGPA/ DGVS/03705/17; SGPA/DGVS/01186/17). La captura, el sacrificio y la recolección de muestras biológicas en los murciélagos estudiados fueron aprobadas por el Comité de Bioética de la Facultad de Medicina Veterinaria y Zootecnia (FMVZ) de la Universidad Autónoma de Yucatán (UADY) (acta: CB-CCBA-I-2018-001).

Capturas y sitios de estudio. Las capturas se realizaron como parte de un proyecto cuyo objetivo era la identificación de especies de mamíferos silvestres, potenciales reservorios del virus Ébola en el sureste de México. Por lo tanto, se decidió trabajar en sitios con fácil acceso y que contaran con las instalaciones e infraestructura mínima para montar un laboratorio en la cual fueron procesados los murciélagos y otros animales capturados (no incluidos en la presente investigación).

Las capturas se realizaron en mayo, agosto y septiembre de 2017 en tres sitios de estudio. La primera captura se realizó en el Centro de Estudios para la Conservación e Investigación de la Vida Silvestre (CECIVS) (1956'-1957' N y $90^{\circ} 22^{\prime \prime}-90^{\circ} 22^{\prime} \mathrm{W}$ ) ubicado en el municipio de Hampolol, en el estado de Campeche. Este sitio tiene un clima cálido subhúmedo, temperatura media anual de $26.1^{\circ} \mathrm{C}$ y precipitación pluvial anual superior a los $1.027 \mathrm{~mm}$. La superficie forestal está representada por distintos tipos de selva como: mediana subcaducifolia, mediana subperennifolia y baja subperennifolia inundable, vegetación acuática y vegetación secundaria. Actualmente, esta vegetación presenta cierto grado de alteración ya que el CECIVS fue parte de un asentamiento prehispánico y posteriormente de una hacienda (12).

La segunda captura se realizó en una explotación pecuaria $\left(21^{\circ} 24^{\prime}-21^{\circ} 23^{\prime} \mathrm{N}\right.$ y $88^{\circ} 30^{\prime}-88^{\circ} 19^{\prime} \mathrm{W}$ ) ubicada en el municipio de Panabá, perteneciente al estado de Yucatán. Esta zona tiene un clima cálido subhúmedo con lluvias en verano, una temperatura media anual de 24 a $26^{\circ} \mathrm{C}$ y una cantidad de lluvia durante el invierno que puede variar entre 600 y 1.500 mm. La vegetación sobresaliente es la selva baja caducifolia. Sin embargo, debido a actividades humanas en la zona (principalmente agropecuarias y agrícolas), esta ha sido severamente transformada (13).

La tercera captura se realizó en la FMVZ-UADY $\left(20^{\circ} 49^{\prime}-20^{\circ} 51^{\prime} \mathrm{N}\right.$ y $\left.89^{\circ} 38^{\prime}-89^{\circ} 39^{\prime} \mathrm{W}\right)$, situada en el municipio de Mérida, capital de Yucatán. Posee un clima cálido subhúmedo con lluvias en verano, una temperatura media anual superior a los $26^{\circ} \mathrm{C}$ y una precipitación pluvial anual entre los 675 y 975 mm. La mayor parte de la superficie está cubierta de vegetación secundaria con diferentes estadios de regeneración, destacando la de 20 a 30 años ( $85 \%$ de la superficie del total); el resto $(15 \%)$ se encuentra repartido en terrenos con usos agrícolas (milpas, pastizales, henequenales u otros cultivos) o pecuarios, solares (huertos familiares) o áreas con algún tipo de construcción (calles y viviendas) (14).

Procesamiento de murciélagos y toma de muestras biológicas. En cada sitio se capturó hasta tres noches consecutivas. Se colocaron tres redes de niebla $(12.0 \mathrm{~m} \times 2.6 \mathrm{~m})$ en lugares cercanos a reservorios de agua, árboles frutales y cuevas. Las redes se abrieron durante cinco 
horas (18:00 a 23:00 h), horario en el cual se observó una mayor actividad de diferentes grupos de murciélagos, llevándose a cabo las revisiones cada 20 minutos.

Los murciélagos capturados fueron retirados de las redes utilizando guantes de carnaza y se colocaron en bolsas de tela para transportarlos al laboratorio temporal montado para su procesamiento dentro de los sitios de estudio. Todos los ejemplares se identificaron utilizando claves taxonómicas (15).

A todos los murciélagos se les aplicó la eutanasia con sobredosis de pentobarbital sódico vía intraperitoneal, previa anestesia con isoflurano, como se describió previamente (16). Posteriormente, se realizó una necropsia para recolectar una porción de riñón que se depositó en viales estériles de $1.5 \mathrm{ml}$ (Eppendorf ${ }^{\circledR}$, Alemania), embebida en etanol absoluto. El personal involucrado en el sacrificio de los animales utilizó doble guante de látex, mascarilla especializada, bata desechable, zapatos cerrados, etc., para prevenir el contacto con la orina, heces, saliva o sangre de los murciélagos.

Las porciones de riñón se preservaron a $4^{\circ} \mathrm{C}$ durante su traslado al Laboratorio de Enfermedades Emergentes y Reemergentes (LEER) del Centro de Investigaciones Regionales "Dr. Hideyo Noguchi" (CIR)-UADY, donde se almacenaron a $-80^{\circ} \mathrm{C}$ hasta su uso en la extracción de ADN total.

\section{Extracción total de ADN e identificación de}

Leptospira. Todos los tejidos fueron lavados con agua bidestilada durante aproximadamente cinco minutos para retirar el exceso de alcohol y afectar lo menos posible la calidad del ADN extraído.

La extracción de ADN total del tejido renal se realizó según lo descrito en el kit DNeasy ${ }^{\circledR}$ Blood \& Tissue (QIAGEN ${ }^{\circledR}$, Alemania), previa digestión con proteinasa K (Omega Bio-tek ${ }^{\circledR}$ Inc., Estados Unidos de América [EUA]). Posteriormente, se cuantificó y evaluó en un espectrofotómetro (NanoDrop $2000^{\mathrm{TM}}$, Thermo Scientific ${ }^{\circledR}$, EUA) y finalmente, se conservó a $-70^{\circ} \mathrm{C}$ hasta su empleo en la detección molecular.

Para identificar la infección con Leptospira se ejecutaron dos reacciones en cadena de la polimerasa (PCR) convencionales, buscando la amplificación de dos fragmentos distintos del gen $16 S-r R N A$.
En la primera se utilizaron los oligonucleótidos 16S3 (5'-ATCCTCATGGCCTTTATGTC-3') (sentido) y $16 \mathrm{SR}$ ( $5^{\prime}$-GTCCGCCTACACACCCTTTAC-3') (antisentido) previamente descritos (17), los cuales amplifican un segmento de 150 pares de bases ( $p b)$. Las concentraciones finales de los reactivos, en un volumen final de $25 \mu \mathrm{l}$, fueron: PCR Buffer 1X, $2.5 \mathrm{mM}$ de $\mathrm{MgCl}_{2}, 0.2 \mathrm{mM}$ de dNTP's, $0.2 \mu \mathrm{M}$ de cada oligonucleótido, $1 U$ de Taq polimerasa (Thermo Scientific ${ }^{\circledR}$, EUA) y cuanto basta para (c.b.p.) de agua grado biología molecular. Las condiciones empleadas en el termociclador fueron: desnaturalización inicial a $95^{\circ} \mathrm{C}$ por cinco minutos, seguido de 34 ciclos con etapas de $95^{\circ} \mathrm{C}$ por 30 segundos, $49^{\circ} \mathrm{C}$ por 30 segundos y $72^{\circ} \mathrm{C}$ por 30 segundos. La extensión final fue a $72^{\circ} \mathrm{C}$ por cinco minutos.

La segunda PCR se realizó únicamente con las extracciones positivas a la reacción previa. Los oligonucleótidos utilizados fueron 16S4 (5'AGTGAACGGGATTAGATACC-3') (sentido) y $16 \mathrm{S6}$ (5'- CCTAGACATAAAGGCCATGA-3') (antisentido) (18), los cuales amplifican un segmento (diferente al de la primera reacción) de 440 pb del gen mencionado. El volumen y las concentraciones finales de cada reactivo fueron iguales a las de la primera PCR (150 pb). Las condiciones del termociclador fueron: desnaturalización inicial a $95^{\circ} \mathrm{C}$ por cinco minutos, seguido de 34 ciclos con etapas de $95^{\circ} \mathrm{C}$ por 30 segundos, $58^{\circ} \mathrm{C}$ por 30 segundos y $72^{\circ} \mathrm{C}$ por 30 segundos. La extensión final fue a $72^{\circ} \mathrm{C}$ por cinco minutos.

En todas las reacciones se incluyó un control positivo (ADN de Leptospira tipificada como $L$. interrogans) y control negativo (agua estéril). La electroforesis se realizó en geles de agarosa $(1 \%)$, teñidos con bromuro de etidio. Los resultados se registraron con un sistema de foto-documentación (Biorad ${ }^{\circledR}$, EUA).

Análisis bioinformático. Debido a limitaciones en el recurso económico, únicamente algunos productos positivos a la segunda reacción (440 pb) se purificaron con ayuda del kit Gel DNA Recovery (Zymoclean $\left.{ }^{\circledR}, \mathrm{EUA}\right)$, siguiendo las instrucciones establecidas por la casa comercial y se enviaron a secuenciación por el método de Sanger al laboratorio privado DYMIGEN ${ }^{\circledR}$ (Mérida, México). Los productos enviados se seleccionaron según su concentración y pureza, obtenidas por NanoDrop2000 ${ }^{\mathrm{TM}}$ (Thermo Scientific ${ }^{\circledR}$, EUA). 
Con las secuencias recibidas (en sentidos forward y reverse) se generó una secuencia consenso (eliminando los fragmentos correspondientes a los oligonucleótidos 16S4 y 16S6) con el software MEGA V7.0 ${ }^{\circledR}$ y se analizaron con la herramienta Basic Local Alignment Search (BLAST), utilizando el algoritmo Megablast ${ }^{\circledR}$, ambos desarrollados por el National Institutes of Health (NIH), con el objetivo de conocer la identidad y cobertura de las especies de Leptospira en los murciélagos infectados.

\section{RESULTADOS}

Con un esfuerzo de muestreo de 59 horas/red, se capturaron un total de 69 murciélagos repartidos en cuatro familias: Noctilionidae, Mormoopidae, Phyllostomidae y Vespertilionidae, y ocho especies: Noctilio leporinus, Pteronotus parnellii, Glossophaga soricina, Carollia sowelli, Artibeus jamaicensis, A. lituratus, Chiroderma villosum y Rhogeessa aeneus. Cinco especies capturadas pertenecieron a la familia Phyllostomidae. Artibeus jamaicensis fue la especie con el mayor porcentaje de ejemplares capturados (59.4\%, 41/69). El sitio con el mayor porcentaje de capturas fue el CECIVS (36.2\%, 25/69), siendo también el que contó con el mayor número de especies y familias capturadas (Tabla 1 ). Respecto a los hábitos alimenticios se capturaron especies piscívoras, frugívoras, frugívoras/ nectarívoras e insectívoras.

La PCR para la detección del gen 16S-rRNA arrojó una frecuencia global de infección de $21.7 \%$ (15/69). De los ejemplares infectados, 11 fueron A. jamaicensis $(73.4 \%)$, dos P. parnellii (13.3\%) y dos C. villosum (13.3\%).
En cada sitio de estudio se identificó por lo menos un individuo infectado, siendo la FMVZ en el que mayor número se obtuvo con ocho especímenes $(53.3 \%, 8 / 15)$, todos pertenecientes a la especie A. jamaicensis. Los ejemplares infectados de $P$. parnellii y $C$. villosum fueron capturados en el CECIVS y Panabá, respectivamente. La información correspondiente únicamente a los murciélagos positivos a la infección se presenta en la tabla 2.

Tabla 2. Sitio de estudio, especie, número total de individuos capturados por especie y de individuos positivos por especie a la infección con Leptospira en los murciélagos estudiados de Campeche y Yucatán, México.

\begin{tabular}{clcc}
\hline $\begin{array}{c}\text { Sitio de } \\
\text { estudio }\end{array}$ & Especie & \#ICE & \#IPE \\
\hline \multirow{2}{*}{ CECIVS } & Pteronotus parnellii & 6 & $2(33.3)$ \\
& Artibeus jamaicensis & 7 & $2(28.6)$ \\
\multirow{2}{*}{ Panabá } & Chiroderma villosum & 5 & $2(40.0)$ \\
& Artibeus jamaicensis & 12 & $1(8.33)$ \\
FMVZ & Artibeus jamaicensis & 22 & $8(36.4)$ \\
\hline
\end{tabular}

\#ICE: Número total de individuos capturados por especie. \#IPE: Número de individuos positivos por especie (\%)

El análisis bioinformático arrojó un 99.0\% de identidad y cobertura para las especies patógenas Leptospira noguchii, L. borgpetersenii y L. santarosai para los productos positivos de los murciélagos $P$. parnellii y $C$. villosum, siendo L. borgpetersenii la única especie identificada en ambos (Tabla 3). El número de pb que se utilizaron al momento de brindar estos valores de identidad fue de 440.

Tabla 1. Familia, especie y número de murciélagos capturados para cada sitio de estudio en Campeche (CECIVS) y Yucatán (Panabá y FMVZ).

\begin{tabular}{|c|c|c|c|c|c|}
\hline \multirow{3}{*}{ Familia } & \multirow{3}{*}{ Especie } & \multicolumn{3}{|c|}{ Individuos capturados por sitio de estudio } & \multirow{3}{*}{$\begin{array}{l}\text { Total de individuos } \\
\text { capturados }(\%)\end{array}$} \\
\hline & & \multirow{2}{*}{$\begin{array}{c}\text { Campeche } \\
\text { CECIVS }\end{array}$} & \multicolumn{2}{|c|}{ Yucatán } & \\
\hline & & & Panabá & FMVZ & \\
\hline Noctilionidae & Noctilio leporinus & 6 & 0 & 0 & $6(8.7)$ \\
\hline Mormoopidae & Pteronotus parnellii & 6 & 0 & 0 & $6(8.7)$ \\
\hline \multirow[t]{5}{*}{ Phyllostomidae } & Glossophaga soricina & 1 & 3 & 0 & $4(5.8)$ \\
\hline & Carollia sowelli & 2 & 0 & 0 & $2(2.9)$ \\
\hline & Artibeus lituratus & 1 & 1 & 0 & $2(2.9)$ \\
\hline & Artibeus jamaicensis & 7 & 12 & 22 & $41(59.4)$ \\
\hline & Chiroderma villosum & 1 & 5 & 0 & $6(8.7)$ \\
\hline Vespertilionidae & Rhogeessa aeneus & 1 & 1 & 0 & $2(2.9)$ \\
\hline \multicolumn{2}{|c|}{ Total (\%): } & $25(36.2)$ & 22 (31.9) & 22 (31.9) & $69(100)$ \\
\hline
\end{tabular}


Tabla 3. Especie de murciélago, sitio de estudio, especie de Leptospira, número de acceso de GenBank de la secuencia homóloga y resultados de análisis $B L A S T$, de los productos de PCR positivos al gen $165-r R N A$ de Leptospira.

\begin{tabular}{ccccc}
\hline $\begin{array}{c}\text { Especie de } \\
\text { murciélago }\end{array}$ & $\begin{array}{c}\text { Sitio de } \\
\text { estudio }\end{array}$ & $\begin{array}{c}\text { Especie de } \\
\text { Leptospira }\end{array}$ & \#AG & AIC \\
\hline $\begin{array}{c}\text { Pteronotus } \\
\text { parnellii }\end{array}$ & CECIVS & Santarosai & CP028377.1 & 99.0 \\
& Borgpetersenii & MH059524.1 & 99.0 \\
$\begin{array}{c}\text { Chiroderma } \\
\text { villosum }\end{array}$ & Panabá & Borgpetersenii & AY995713.1 & 99.0 \\
\hline
\end{tabular}

\#AG: Número de acceso GenBank de la secuencia homóloga; AIC: Análisis BLAST (\%), identidad y cobertura

\section{DISCUSIÓN}

Los murciélagos de la península de Yucatán han sido identificados como reservorios de distintos virus del género Flavivirus (6) y como hospederos accidentales de los protozoarios Toxoplasma gondii (16) y Trypanosoma cruzi $(19,20)$, por lo que este estudio aumenta el conocimiento sobre la participación de estos mamíferos en el ciclo epidemiológico de agentes infecciosos emergentes o reemergentes, señalados en la región con relevancia en salud pública y animal, como lo es Leptospira (21).

En Yucatán, la infección con leptospiras patógenas ha sido descrita en riñones de roedores capturados en ambientes peridomésticos y silvestres $(17,22,23,24)$, mientras que, en Campeche la infección ha sido detectada en roedores silvestres (25), por lo que los presentes hallazgos son los primeros en murciélagos de Yucatán y Campeche, México.

El establecimiento y la colonización de Leptospira en el tejido renal de los reservorios animales, han sido relacionados con el aumento de casos nuevos y en la generación de brotes de leptospirosis en seres humanos o animales domésticos (hospederos susceptibles) de algunas regiones endémicas tropicales, debido a la excreción y dispersión de bacterias por su orina y la subsecuente contaminación ambiental o de cuerpos naturales de agua en donde las bacterias sobreviven y se mantienen infectivas por periodos variables $(3,4,26)$.
Interesantemente, la frecuencia de infección encontrada en el tejido renal de los murciélagos utilizados en este trabajo (21.7\%), es más elevada en comparación con las obtenidas en tejido renal de otros reservorios capturados en Yucatán como ratones $(1.5 \%, 2 / 130)(17)$, ratas $(1.4 \%, 1 / 73)(23)$ y roedores silvestres $(4.5 \%$, $1 / 22$ ) (24) y también en roedores silvestres capturados en Campeche (20\%, 2/10) (25), lo cual posiblemente esté relacionado con un contacto mayor y frecuente entre los murciélagos y las leptospiras que permanecen infectivas en el ambiente húmedo en los que estos animales suelen vivir, descansar o transitar (27). Sin embargo, son necesarias investigaciones epidemiológicas para confirmar esta hipótesis.

Por otra parte, esta misma frecuencia de infección es menor en comparación con la reportada previamente por Ballados-González et al. (10) en murciélagos de Veracruz, México (30.9\%, 25/81). También es menor en comparación con estudios realizados en murciélagos de otros países del continente americano como Colombia $(26.9 \%, 7 / 26)(28)$ y Brasil $(39.1 \%, 36 / 92)$ (29), pero es mayor en comparación con las investigaciones en murciélagos de Argentina $(2 \%, 14 / 70)(30)$, Perú $(3.4 \%, 20 / 2,237)$ (31) y otra de Brasil $(2 \%, 6 / 343)$ (32). Todos estos hallazgos muestran variaciones amplias en las frecuencias de infección con Leptospira en este grupo de mamíferos (28).

Aunque se conocen diversos estudios que han identificado leptospiras patógenas en murciélagos alrededor del mundo, existe controversia sobre su participación en el ciclo de transmisión zoonótico de estas bacterias y la consecuente presentación de la enfermedad $(8,27)$. No obstante, debido a los severos y numerosos cambios antropogénicos (principalmente en el uso de suelo), la capacidad de movilidad de los quirópteros y los elevados números de sus poblaciones, la probabilidad de contacto entre estos animales y los seres humanos se ha incrementado, junto con el riesgo de transmisión de leptospiras patógenas $(28,32)$.

Se han formulado algunas hipótesis sobre los mecanismos de transmisión de Leptospira en los murciélagos, independientemente de sus hábitos alimenticios. Una de ellas es el contacto con orina de otros individuos portadores pertenecientes a la misma colonia o grupo, debido al marcado comportamiento gregario que permite que murciélagos de distintas especies o de una sola especie coexistan en un mismo hábitat (8), aunado a la conducta de acicalamiento que propicia la ingesta accidental de restos (gotas) 
de orina presentes en el cuerpo o en las alas (33). De la misma manera, el consumo de agua en cuerpos naturales o artificiales contaminados con leptospiras viables puede ser otra vía de transmisión, como sucede habitualmente con otro tipo de mamíferos (26), lo cual puede explicar la diversidad de especies de murciélagos infectados (al beber de una misma fuente de agua contaminada), así como las prevalencias elevadas y las distintas especies de leptospiras que infectan a estos animales (9). Por último, el contacto indirecto con suelo húmedo contaminado con leptospiras viables, también ha sido sugerido como un posible mecanismo de transmisión (29), sobre todo en especies que consumen insectos con restos de sustrato en su cuerpo o extremidades (34).

El presente estudio permitió conocer que un mayor número de especies de murciélagos son portadoras de Leptospira en México, al identificarse la infección en $P$. parnellii y $C$. villosum. Anteriormente, Ballados-González et al (10) reportaron la infección en $A$. lituratus, C. godmani y $D$. rotundus.

Artibeus jamaicensis es la única especie positiva para Yucatán y Campeche que previamente ha sido descrita como infectada con Leptospira para el continente americano en la isla de Trinidad (35).

Con relación a las especies patógenas de Leptospira, Ballados-González et al (10) describieron la infección con L. noguchii, $L$. weilii y $L$. interrogans, por lo que, según estos registros, esta investigación reporta por primera vez la infección con $L$. borgpetersenii y $L$. santarosai en murciélagos de México. Leptospira noguchii es la única especie localizada en murciélagos de los tres estados (Veracruz, Campeche y Yucatán). Asimismo, con referencia a las leptospiras patógenas reportadas en los trabajos realizados en murciélagos del continente americano $(28,29,30,31,32,35)$, esta investigación identifica por primera vez la infección con $L$. santarosai, lo cual también es probable a nivel mundial $(8,9)$.

Otro de los aportes de este estudio, es el incremento en la diversidad de especies patógenas de Leptospira (borgpetersenii, santarosai y noguchii) en portadores renales de Yucatán y Campeche, ya que previamente se han descrito $L$. interrogans en ratones sinantrópicos (M. musculus) y silvestres como Heteromys gaumeri y Ototylomys phyllotis $(17,23,24)$ y Leptospira kirschneri en $R$. rattus (17).

Desafortunadamente, los productos positivos de $A$. jamaicensis (que fue la especie con el mayor número de captura y positivos a la infección en el presente trabajo) no pudieron ser enviados a secuenciación y analizados, lo cual significa una limitación en los resultados, ya que probablemente estos individuos estén infectados con otras especies de Leptospira prevalentes en la región. Por este motivo, es necesario realizar una nueva captura para determinar el valor epidemiológico de esta especie particular en la transmisión de Leptospira en la región.

La presencia de murciélagos portadores renales de Leptospira puede tener implicaciones en la salud pública. Vashi et al (7) describieron un caso de leptospirosis en una persona adulta, adquirida por contacto indirecto con un murciélago que probablemente contaminó con orina un cuerpo artificial de agua. Considerando lo anterior y las características del CECIVS como lo son los extensos cuerpos naturales de agua con acceso al público, esta vía de transmisión podría presentarse en los usuarios al infectarse con bacterias contenidas en el agua excretadas por murciélagos (36). Por otra parte, teniendo en cuenta que dos de las especies de murciélagos generalistas (adaptadas a las viviendas y otras construcciones) capturadas en Yucatán y Campeche, fueron positivas a la infección con Leptospira, el riesgo de transmisión a personas y animales domésticos por contacto con su orina puede incrementarse $(30,32)$. En este sentido, la especie $A$. jamaicensis ya ha sido identificada en los peridomicilios de viviendas rurales de Yucatán (19).

Por otro lado, la transmisión indirecta a los seres humanos y animales domésticos de las leptospiras que infectan a los murciélagos puede ocurrir por la participación de otros reservorios, particularmente aquellos que habitan en los mismos hábitats y se alimentan en el suelo, tales como ratones (M. musculus) o ratas ( $R$. rattus) $(11,31)$; los cuales han sido reconocidos en el interior o en los alrededores próximos de viviendas rurales y suburbanas de Yucatán (23).

\section{Conflicto de intereses}

Los autores del presente trabajo declaramos que no existe conflicto de intereses.

\section{Agradecimientos}

A Yessica Gurubel, Emir Palomo y Naomi Cuevas, por su apoyo en la captura. A Irene Castillo Rivas por la traducción del resumen. El trabajo de campo fue financiado por el proyecto "Análisis y evaluación de los probables vectores y reservorios del virus del Ébola en México", CONACYT-251053, apoyado por el Fondo Sectorial de Investigación para la Educación. El trabajo de laboratorio fue financiado por el Laboratorio de Enfermedades Emergentes y Reemergentes del CIR, UADY. 


\section{REFERENCIAS}

1. Vincent AT, Schiettekatte O, Goarant C, Neela VK, Bernet E, Thibeaux R, et al. Revisiting the taxonomy and evolution of pathogenicity of the genus Leptospira through the prism of genomics. PLoS Negl Trop Dis. 2019; 13(5):e0007270. https:// doi.org/10.1371/journal.pntd.0007270

2. Sánchez-Montes S, Espinosa-Martínez DV, Ríos-Muñoz CA, Berzunza-Cruz M, Becker I. Leptospirosis in Mexico: epidemiology and potential distribution of human cases. PLoS One. 2015; 10(7):e0133720. https://doi. org/10.1371/journal.pone.0133720

3. Torres-Castro M, Hernández-Betancourt $S$, Agudelo-Flórez P, Arroyave-Sierra E, ZavalaCastro J, Puerto FI. Revisión actual de la epidemiología de la leptospirosis Rev Med Inst Mex Seguro Soc. 2016; 54(5):620625. http://revistamedica.imss.gob. $\mathrm{mx/}$ editorial/index.php/revista medica/article/ view/486/990

4. Agudelo-Flórez $P$, Londoño $A F$, Quiroz VH, Angel JC, Moreno N, Loaiza ET, et al. Prevalence of Leptospira spp. in urban rodents from a groceries trade center of Medellin, Colombia. Am J Trop Med Hyg. 2009; 81(5):906-910. https://doi. org/10.4269/ajtmh.2009.09-0195

5. Han HJ, Wen HL, Zhou CM, Chen FF, Luo LM, Liu JW, et al. Bats as reservoirs of severe emerging infectious diseases. Virus Res. 2015; 205:1-6. https://doi.org/10.1016/j. virusres.2015.05.006

6. Machain-Williams $C$, López-Uribe $M$, Talavera-Aguilar L, Carrillo-Navarrete J, Vera-Escalante L, Puerto-Manzano F, et al. Serologic evidence of flavivirus infection in bats in the Yucatan Peninsula of Mexico. J Wildl Dis. 2013; 49(3):684-689. https:// doi.org/10.7589/2012-12-318

7. Vashi NA, Reddy P, Wayne DB, Sabin B. Bat-associated leptospirosis. J Gen Intern Med. 2010; 25(2):162-164. https://doi. org/10.1007/s11606-009-1210-7
8. Dietrich M, Mühldorfer K, Tortosa $P$, Markotter W. Leptospira and bats: story of an emerging friendship. PLoS Pathog. 2015; $11:$ e1005176. https://doi.org/10.1371/ journal.ppat. 1005176

9. Bastiani CE, Ramírez NN, Alegre EA, Ruiz RM. Identificación y caracterización de refugios de quirópteros en la Ciudad de Corrientes, Argentina. Rev Vet. 2012; 23(2):104-109. http://revistas.unne.edu.ar/index.php/vet/ article/view/1787

10. Ballados-González GG, Sánchez-Montes $S$, Romero-Salas D, Colunga-Salas $P$, Gutiérrez-Molina R, León-Paniagua $L$, et al. Detection of pathogenic Leptospira species associated with phyllostomid bats (Mammalia: Chiroptera) from Veracruz, Mexico. Transbound Emerg Dis. 2018; 65(3):773-781. https://doi.org/10.1111/ tbed.12802

11. Tulsiani SM, Cobbold RN, Graham GC, Dohnt MF, Burns MA, Leung LK, et al. The role of fruit bats in the transmission of pathogenic leptospires in Australia. Ann Trop Med Parasitol. 2011; 105(1):71-84. https://doi. org/10.1179/136485911X12899838413501

12. Gutiérrez Báez C, Zamora-Crescencio $P$, Puc-Garrido EC. Estructura y composición florística de la selva mediana subperennifolia de Hampolol, Campeche, México. For Ver. 2013; 15(1):1-8. https://www.redalyc.org/ pdf/497/49728291001.pdf

13. Magaña-Rueda S, Santos-Flores J, Castillo Caamal J. Identificación y uso de la vegetación nativa en ranchos de doble propósito en el Oriente de Yucatán. Bioagrociencias. 2015; 8(1):17-22. http:// www.ccba.uady. $\mathrm{mx} /$ bioagro/V8N1/BC\%20 8.1\%20Vegetacion $\% 20$ nativa $\% 20$ en $\% 20$ ranchos.pdf

14. Panti-May J, Hernández-Betancourt S, Ruiz-Piña H, Medina-Peralta S. Abundance and population parameters of commensal rodents present in rural households in Yucatan, Mexico. Int Biodeter Biodegr. 2012; 66(1):77-81. https://doi.org/10.1016/j. ibiod.2011.10.006 
15. Reid F. A field guide to the mammals of America Central and Southeast México. 2a ed. Unites States of America: Oxford University Press; 2009. https://www. amazon.com/Mammals-Central-AmericaSoutheast-Mexico/dp/0195343239

16. Torres-Castro $M$, Muñoz-Dueñas $D$, Hernández-Betancourt S, Bolio-González M, Noh-Pech $\mathrm{H}$, Peláez-Sánchez R, et al. Infección con Toxoplasma gondii (Eucoccidiorida: Sarcocystidae) en murciélagos de Campeche y Yucatán, México. Rev Biol Trop. 2019; 67(3):633-642. https://doi.org/10.15517/ RBT.V67I2.35147

17. Torres-Castro MA, Gutiérrez-Ruiz $E$, Hernández-Betancourt, S, Peláez-Sánchez R, Agudelo-Flórez P, Guillermo-Cordero L, et al. First molecular evidence of Leptospira spp. in synanthropic rodents captured in Yucatan, Mexico. Revue Méd Vét. 2014; 165(78):213-218. https://www.revmedvet. com/2014/RMV165 213 218.pdf

18. Haake D, Suchard M, Kelley M, Dundoo M, Alt D, Zuerner R. Molecular evolution and mosaicism of Leptospira outer membrane proteins involves horizontal DNA transfer. J Bacteriol. 2004; 186(9):2818-2828. https://doi.org/10.1128/jb.186.9.28182828.2004

19. Córdova-Aldana D, Escobedo-Ortegón JE, Hernández-Betancourt S, Ruiz-Piña HA. Los murciélagos en el ciclo de transmisión de Trypanosoma cruzi en el peridomicilio rural. En: J Pacheco-Castro, JA Lugo-Pérez, L Tzuc-Canché, HA Ruiz-Piña (Eds.), Estudios multidisciplinarios de las enfermedades zoonóticas y ETVs en Yucatán. 1er Ed. México: Universidad Autónoma de Yucatán; 2013. http://www.libreria.uady.mx/viewlib. php?i=1216

20. López-Cancino SA, Tun-Ku E, De la CruzFelix HK, Ibarra-Cerdeña CN, Izeta-Alberdi A, Pech-May A, et al. Landscape ecology of Trypanosoma cruzi in the southern Yucatan Peninsula. Acta Trop. 2015; 151:58-72. https://doi.org/10.1016/j.actatropica
21. Reyes-Novelo E, Ruíz-Piña H, EscobedoOrtegón J, Rodríguez-Vivas I, Bolio-González M, Polanco-Rodríguez Á, et al. Situación actual y perspectivas para el estudio de las enfermedades zoonóticas emergentes, reemergentes y olvidadas en la península de Yucatán, México. Trop Subtrop Agroecos. 2011; 14(1):35-54. http://www.revista. ccba.uady.mx/ojs/index.php/TSA/article/ view/659

22. Torres-Castro M, Guillermo-Cordero L, Hernández-Betancourt $S$, Gutiérrez-Ruíz $\mathrm{E}$, Agudelo-Flórez P, Peláez-Sánchez R, et al. First histopathological study in kidneys of rodents naturally infected with Leptospira pathogenic species from Yucatan, Mexico. Asian Pac J Trop Med. 2016; 9(2):145-147. https://doi.org/10.1016/j. apjtm.2016.01.018

23. Panti-May JA, DE Andrade RRC, GurubelGonzález Y, Palomo-Arjona E, Sodá-Tamayo L, Meza-Sulú J, et al. A survey of zoonotic pathogens carried by house mouse and black rat populations in Yucatan, Mexico. Epidemiol Infect. 2017; 145(11):2287-2295. https:// doi.org/10.1017/S0950268817001352

24. Torres-Castro M, Cruz-Camargo B, MedinaPinto R, Reyes-Hernández B, Moguel-Lehmer $C$, Medina $R$, et al. Detección molecular de leptospiras patógenas en roedores sinantrópicos y silvestres capturados en Yucatán, México. Biomedica. 2018; 38(0):51-58. https://doi.org/10.7705/ biomedica.v38i3.3938.

25. Espinosa-Martínez DV, Sánchez-Montes DS, León-Paniagua L, Ríos-Muñoz CA, BerzunzaCruz M, Becker I. New wildlife hosts of Leptospira interrogans in Campeche, Mexico. Rev Inst Med Trop Sao Paulo. 2015; 57(2):181-183. https://doi.org/10.1590/ s0036-46652015000200015.

26. Chávez Á, Flores-Somarriba $B$, Soto $A$, Sheleby-Elías J, Duttmann C, Jiménez $\mathrm{E}$, et al. Detección de Leptospira spp. en animales y muestras ambientales de áreas peridomésticas en Nicaragua. Rev Panam Salud Publica. 2018; 42:e26. https://doi. org/10.26633/RPSP.2018.26 
27. Hui-Ju $H$, Hong-Ling $W$, Jian-Wei L, XiangRong $\mathrm{Q}$, Min Z, Li-Jun $W$, et al. Pathogenic Leptospira species in insectivorous bats, China, 2015. Emerg Infect Dis. 2018; 24(6):1123-1126. https://doi.org/10.3201/ eid2406.171585

28. Mateus J, Gómez N, Herrera-Sepúlveda MT, Hidalgo M, Pérez-Torres J, Cuervo C. Bats are a potential reservoir of pathogenic Leptospira species in Colombia. J Infect Dev Countr. 2019; 13(4):278-283. https://doi. org/10.3855/jidc. 10642

29. Mayer FQ, Dos-Reis EM, Bezerra AVA, Cerva C, Rosa J, Cibulski SP, et al. Pathogenic Leptospira spp. in bats: Molecular investigation in Southern Brazil. Comp Immunol Microbiol Infect Dis. 2017; 52:14-18. https://doi.org/10.1016/j. cimid.2017.05.003

30. Ramirez NN, Alegra EA, Ruiz RM, De Biasio $M B$, Bastiani CE. Detección de leptospiras patógenas en tejido renal de murciélagos de Corrientes, Argentina. Rev Vet. 2014; 5(1):16-20. http://revistas.unne.edu.ar/ index.php/vet/article/view/543

31. Matthias MA, Díaz MM, Campos KJ, Calderon $M$, Willig MR, Pacheco V, et al. Diversity of bat-associated Leptospira in the Peruvian Amazon inferred by bayesian phylogenetic analysis of $16 \mathrm{~S}$ ribosomal DNA sequences. Am J Trop Med Hyg. 2005; 73(5), 964974. http://www.ajtmh.org/docserver/ fulltext/14761645/73/5/0730964.pdf?exp ires $=1567607783 \& i d=$ id\&accname $=$ guest $\underline{\text { \&checksum }=29 D 48246131873730 \mathrm{D} 35544}$ F57654D6E
32. Bessa TA, Spichler A, Chapola EG, Husch $A C$, de Almeida MF, Sodré MM, et al. The contribution of bats to leptospirosis transmission in Sao Paulo City, Brazil. Am J Trop Med Hyg. 2010; 82(2):315-317. https:// doi.org/10.4269/ajtmh.2010.09-0227

33. Smythe LD, Field HE, Barnett LJ, Smith CS, Dohnt MF, Symonds ML, et al. Leptospiral antibodies in flying foxes in Australia. J Wildl Dis. 2002; 38(1):182-186. https:// doi.org/10.7589/0090-3558-38.1.182

34. Gonzalez-Astudillo $V$, Bustamante-Rengifo JA, Bonilla Á, Lehmicke AJ, Castillo A, Astudillo-Hernández M. Synanthropic cockroaches (Blattidae: Periplaneta spp.) harbor pathogenic Leptospira in Colombia. J Med Entomol. 2016; 53(1):177-182. https://doi.org/10.1093/jme/tjv172

35. Everard CO, Fraser-Chanpong GM, Bhagwandin LJ, Race MW, James AC. Leptospires in wildlife from Trinidad and Grenada. J Wildl Dis. 1983; 19(3):192199. https://doi.org/10.7589/0090-355819.3.192

36. Mgode GF, Mbugi HA, Mhamphi GG, Ndanga D, Nkwama EL. Seroprevalence of Leptospira infection in bats roosting in human settlements in Morogoro municipality in Tanzania. Tanzan J Health Res. 2014; 16(1):23-28. http://dx.doi.org/10.4314/ thrb.v16i1.4 